\title{
ANALISIS PENGELOLAAN KONTEN DIGITAL MARKETING MEDIA SOSIAL INSTITUT FRANÇAIS INDONESIA BANDUNG
}

\author{
Farahma Ayu Almaida, Rah Utami Nugrahani \\ Telkom University Bandung \\ farahmaalmaida@gmail.com, rutamin@telkomuniversity.ac.id
}

\begin{abstract}
ABSTRAK:
Institut Français Indonesia Bandung merupakan pusat kebudayaan dan lembaga pendidikan bahasa Prancis di bawah Kedutaan Besar Perancis. Media sosial Instagram sebagai pemasaran digital yang digunakan untuk memberikan informasi tentang kursus bahasa Prancis dan berbagai informasi tentang acara budaya yang akan diadakan. Melalui Instagram, Institut Français Indonesia Bandung memiliki jumlah pengikut dan posting tertinggi dibandingkan dengan lembaga bahasa asing lainnya di Bandung. Tujuan dari penelitian ini adalah untuk mengetahui strategi pemasaran digital di media sosial Instagram Institut Français Indonesia Bandung berdasarkan empat pilar strategi media sosial Lon Safko dan David K. Brake: komunikasi, kolaborasi, pendidikan, dan hiburan. Metode penelitian yang digunakan adalah pendekatan kualitatif. Data dikumpulkan melalui observasi pada instagram media sosial Institut Français Indonesia Bandung dan wawancara mendalam dengan informan kunci dan informan pendukung untuk mendapatkan data tentang penggunaan strategi media sosial. Hasil dari penelitian ini menjelaskan penggunaan strategi pemasaran digital untuk konten media sosial yang sesuai dan berguna untuk kelangsungan lembaga dalam menyebarkan pesan dan informasi.
\end{abstract}

Kata Kunci: Media Baru, Pemasaran Digital, Strategi Media Sosial

\section{Pendahuluan}

Di zaman yang serba canggih ini, Institut Français Indonesia Bandung menggunakan media sosial sebagai sarana untuk menyebarkan informasi dan media promosi. Kerjasama dalam bidang pendidikan merupakan salah satu target utama dalam pelaksanaan diplomasi kebudayaan Prancis selain dari pengaruh kebudayaan dan bahasa Prancis. Peningkatan kinerja untuk meningkatkan jumlah pelajar Indonesia di Prancis tersebut terlihat dari strategi Prancis untuk mengubah nama pusat kebudayaan Perancis yang bernama Centre Culturel Francais (CCF) menjadi Institut Français yang berpusat di Paris pada tanggal 27 Juli 2010. 
Media sosial Instagram Insitut Français Indonesia Bandung memiliki jumlah followers dan post tertinggi dibandingkan dengan lembaga belajar bahasa asing lain yaitu: CLC dan LBC (berdasarkan hasil olahan penulis tahun 2018). Sehingga dapat dikatakan Institut Français Indonesia Bandung lebih menarik perhatian dan digemari daripada tempat kursus lainnya di Kota Bandung. Berikut merupakan gambaran dari penggunaan media sosial Instagram yang digunakan Institut Français Indonesia Bandung sebagai perbandingan dengan lembaga kursus bahasa asing CLC dan LBC:

Data Media Sosial Lembaga Kursus Bahasa Prancis di Bandung

\begin{tabular}{|c|l|c|c|}
\hline \multirow{2}{*}{ No } & \multicolumn{2}{|c|}{ Lembaga Kursus } & \multicolumn{2}{c|}{ Instagram } \\
\cline { 3 - 4 } & & Followers & Post \\
\hline 1 & Institut Français Indonesia & 3704 & 544 \\
\hline 2 & LBC (Learning Billingual Centre) & 18 & 6 \\
\hline 3 & CLC Bandung & 197 & 59 \\
\hline
\end{tabular}

Sumber: Data Olahan Penulis 2018

Pada tabel di atas menunjukkan bahwa Institut Français Indonesia Bandung berada pada peringkat pertama dengan total 3704 followers dan 544 post. Tabel ini menunjukkan bahwa IFI termasuk lembaga yang sangat memanfaatkan fungsi media sosial Instagram dalam mempromosikan kursus bahasa Prancis serta menyebarkan informasi kegiatan budaya yang akan dilaksanakan sehingga dengan adanya media sosial Instagram ini pesan yang dibagikan akan lebih cepat sampai ke khalayak.

Penelitian ini menggunakan metode kualitatif dengan paradigma post-positivisme. Metode kualitatif adalah metode yang penelitiannya dilakukan pada kondisi yang alamiah 
(natural setting) tanpa adanya tambahan setting dalam penelitian (Sugiyono, 2015:1415). Paradigma menurut Thomas Khun adalah bagaimana peneliti mengetahui realitas sosial yang didasari oleh pola berfikir atau model suatu penyelidikan tertentu yang selanjutnya menghasilkan cara mengetahui yang spesifik (Ikbar, 2012:52)

Sementara, paradigma post-positivisme berpendapat bahwa peneliti tidak mampu mendapatkan fakta dari suatu kenyataan apabila peneliti membuat jarak (distance) dengan kenyataan yang ada. Hubungan peneliti dengan realitas harus bersifat interaktif. Oleh karena itu, digunakan prinsip triangulasi, yaitu penggunaan bermacam-macam metode, sumber data dan data (Tahir, 2011:57-58)

\section{Metode Penelitian}

Metode penelitian yang digunakan dalam penelitian ini adalah metode penelitian kualitatif. Metode ini sering disebut dengan metode penelitian naturalistik karena penelitiannya dilakukan pada kondisis yang alamiah (natural setting) tanpa adanya tambahan setting pada penelitian. Disamping itu, disebut dengan metode kualitatif karena data yang terkumpul dan analisisnya lebih bersifat kualitatif. Penelitian kualitatif memiliki instrument yang tidak lain adalah orang atau human instrument yakni peneliti itu sendiri. Untuk dapat menjadi instrumen, maka peneliti harus memiliki bekal baik mengenai teori atau wawasan yang luas, sehingga mampu bertanya, menganalisis, memotret dan mengkontruksi situassi sosial yang diteliti menjadi lebih jelas dan bermakna (Sugiyono, 2015:14-15).

Landasan berfikir atau paradigma yang digunakan dalam penelitian ini adalah postpositivisme. Paradigma post-positivisme berpendapat bahwa peneliti tidak mampu mendapatkan fakta dari suatu kenyataan apabila peneliti membuat jarak (distance) dengan kenyataan yang ada. Hubungan antara peneliti dengan realitas harus bersifat 
interaktif. Oleh karena itu, digunakan pula prinsip triangulasi yaitu penggunaan bermacam-macam metode, sumber data dan data (Tahir, 2011:57-58).

Informan pada penelitian ini terdiri dari dua informan, yaitu informan utama dan informan pendukung. Dalam penelitian ini, yang menjadi informan utama adalah Ibu Melanie Martini Mareel selaku direktur Institut Français Indonesia Bandung dan Bapak Ricky Arnold Yuniarto selaku penanggung jawab komunikasi dan budaya Institut Français Indonesia Bandung. Selain itu, informan pendukung dalam penelitian ini adalah Bapak Islaminur Pempasa selaku pakar komunikasi.

Metode pengumpulan data menurut (Krisyanto, 2014:95) yaitu teknik atau caracara yang dapat digunakan periset untuk mengumpulkan data. Dalam riset kualitatif dikenal dengan metode pengumpulan data: observasi (field observations), FGD (Focus Group Discussion) dan wawancara mendalam (in-depth interview).

Pada penelitian ini terdapat dua jenis data yang akan digunakan, yaitu: primer dan sekunder. Data primer adalah data yang diperoleh secara langsung dari subjek penelitian, sedangkan data sekunder merupakan data pendukung yang diperoleh dari sumber-sumber lain yang telah terpercaya. Jenis teknik pengumpulan data yang akan digunakan oleh peneliti adalah: observasi, wawancara mendalam serta dokumentasi. Pada penelitian ini, penulis melakukan observasi pada beberapa media sosial Institut Français Indonesia Bandung yaitu Instagram terhitung sejak Agustus 2018 dimana penulis memulai penelitian ini. Tujuan dilakukannya observasi adalah untuk memperdalam dan membuktikan informasi yang diperoleh sehingga data yang didapat dapat dibuktikan kebenarannya. peneliti akan melalukan wawancara secara mendalam dengan beberapa informan terkait permasalahan yang akan dibahas yaitu Ibu Melanie Martini Mareel selaku direktur Institut Français Indonesia Bandung dan Bapak Ricky Arnold Yuniarto bagian komunikasi dan budaya Institut Français Indonesia Bandung. Selain itu, peneliti 
juga akan melakukan wawancara mendalam dengan Bapak Islaminur Pempasa selaku pakar komunikasi. Peneliti akan memperoleh data sekunder dari dokumen-dokumen yang terkait dengan masalah yang akan diteliti, baik berupa foto atau laporan tertulis

\section{Pembahasan}

Menurut Lon Safko dan David K. Brake (2009) strategi media sosial didukung oleh empat pilar yang sangat dibutuhkan untuk mengembangkan media sosial serta agar strategi yang dipilih dapat berjalan dengan baik. Empat pilar strategi medial sosial tersebut adalah:

1. Komunikasi

Pada aspek komunikasi berbicara mengenai perusahaan, layanan, jasa atau merek yang dipasarkan. Brand image produk atau layanan dan pesan iklan yang terpercaya dibutuhkan ketika mengkomunikasikan sebuah pesan. Menurut Lon Safko dan David K. Brake (2009), aspek komunikasi yang baik yaitu mampu membangun percakapan dengan audiens, karena kita tidak dapat mengontrol interaksi dan percakapan pada media sosial, yang dapat dilakukan hanyalah mempengaruhi audiens tersebut. Faktanya, IFI Bandung belum memiliki admin media sosial dan konten manajer khusus untuk mengelola media sosialnya. Konten pada media sosial Instagram @IFI_Bandung yang memuat aspek strategi komunikasi penyebarannya dilakukan oleh setiap bidang penanggungjawab masingmasing, seperti konten pesan kursus disebarkan oleh bidang marketing kursus dan pedagogi, konten pesan kegiatan yang akan dilaksanakan dan informasi umum disebarkan oleh bidang komunikasi dan budaya, konten pesan tentang buku-buku terbaru, film Prancis dan berbagai workshop literasi disebarkan oleh bidang mediatek serta konten pesan mengenai beasiswa dan sekolah lanjutan ke Prancis disebarkan 
oleh bidang Campus France. Hal tersebut dilakukan dalam pengelolaan media sosial Instagram Institut Français Indonesia Bandung agar interaksi komunikasi dapat lebih terarah pada target market masing-masing.

2. Kolaborasi

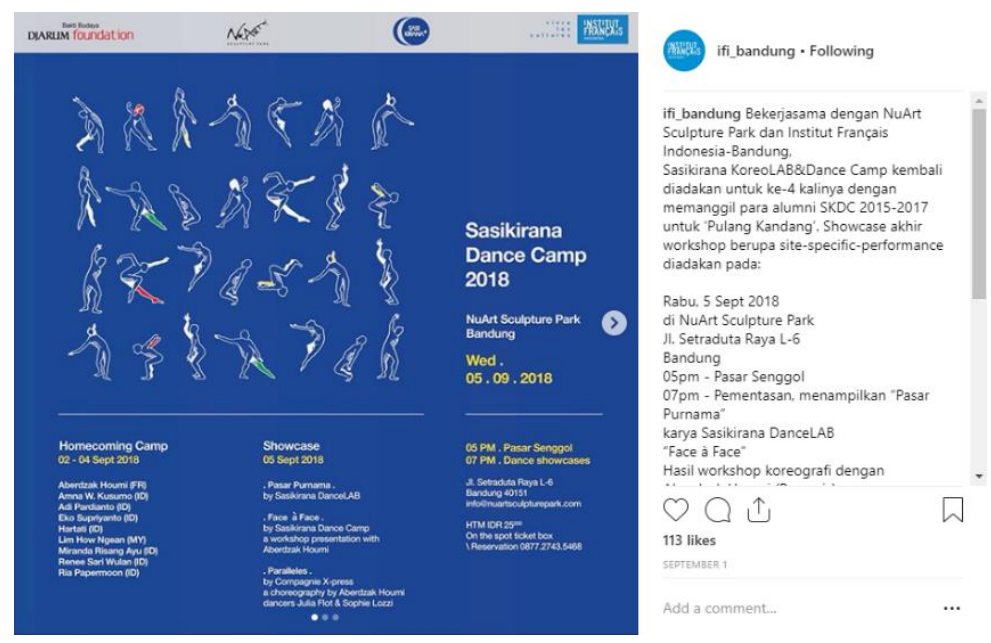

Gambar di atas menunjukkan bahwa Institut Français Indonesia Bandung berkerjasama dengan NuArt Sculpture Park mengadakan Sasikirana KoreoLAB dan Dance Camp ke-4 bertempat di NuArt Sculpture Park. Bentuk penyebaran kolaborasi digital yang dilakukan adalah menyebarkan informasi pada semua media sosial IFI Bandung dan NuArt Sculpture Park.

Pada aspek kolaborasi, perusahaan atau institusi dapat bekerja sama dengan komunitas tertentu untuk menyebarkan sebuah pesan iklan sehingga pesan tersebut akan lebih cepat sampai ke target. Teori Lon Safko dan David K. Brake (2009) mengatakan bahwa kolaborasi yang baik adalah yang mampu menjalin hubungan baik dengan berbagai komunitas. Sehingga, ada timbal balik positif yang didapat antara kedua belah pihak. Institut Français Indonesia Bandung melakukan kolaborasi dengan berbagai komunitas dengan tujuan untuk membangun kerja sama (building partnership) yang baik sehingga nantinya ketika ada kegiatan lain 
akan lebih mudah dalam berkoordinasi, penyebaraan informasi lebih meluas dan kelancaraan saat pelaksanaan kegiatan. IFI Bandung dalam menjalin kolaborasi bukan sekedar sekali atau dua kali dengan komunitas-komunitas tersebut. Karena membangun suatu kerja sama yang baik harus dilakukan dalam waktu jangka panjang dan terus menerus.

\section{Edukasi}

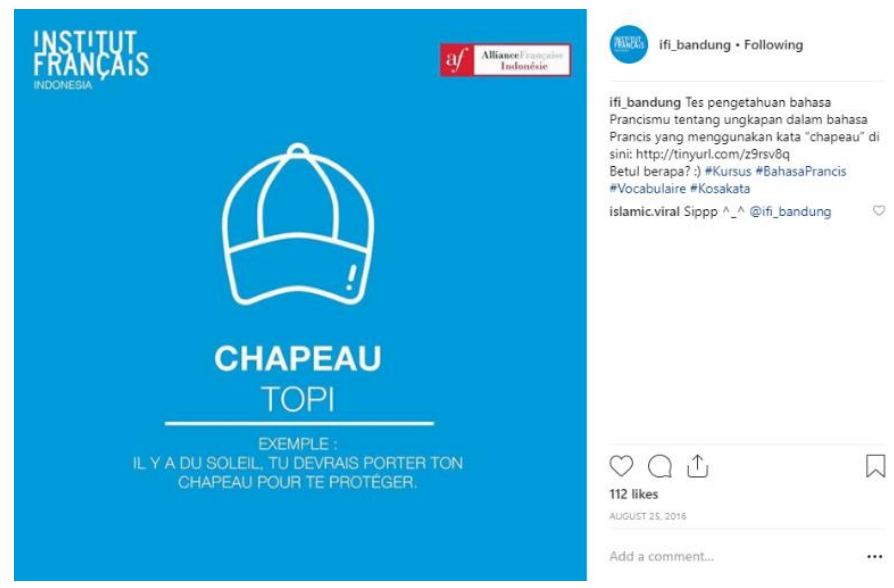

Pada gambar di atas menunjukkan bahwa Institut Français Indonesia Bandung menyebarkan konten edukasi pada media sosial termasuk Instagram mengenai benda-benda dalam bahasa Prancis disertai dengan contoh kalimatnya. Sehingga para pengikut di Instagram dapat mengingat dan memahami Bahasa Prancis dengan mudah.

Pada aspek edukasi, pesan yang disampaikan dapat memberikan edukasi dan inspirasi untuk khalayak sehingga pesan atau informasi yang disebarkan tersebut dapat bermanfaat khususnya dalam kehidupan sehari-hari. Teori dari Lon Safko dan David K. Brake (2009) menjelaskan bahwa dengan adanya konten edukasi pada media sosial mampu membangun ikatan dengan target audiens karena dengan adanya konten edukasi yang bermanfaat merupakan salah satu proses berbagi ilmu secara terus menerus. Media sosial Instagram @IFI_Bandung memuat konten 
edukasi untuk melawan stigma bahwa belajar Bahasa Prancis tidak mudah. Pada kenyataannya kita sering kali tidak sadar bahwa sedang mengucapkan kata-kata dalam Bahasa Prancis seperti café, restaurant, a la carte dan lain-lain.

4. Hiburan
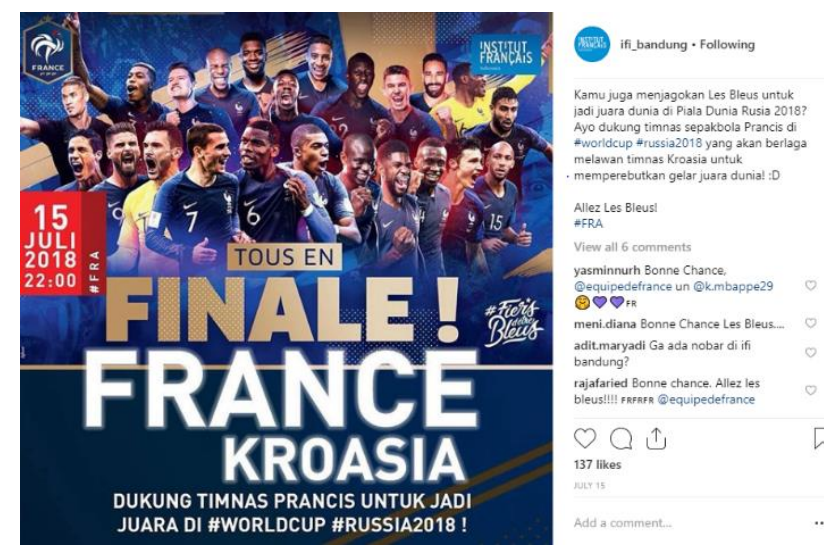

Pada gambar di atas menjelaskan bahwa Institut Français Indonesia Bandung menyebarkan konten hiburan ke media sosial termasuk Instagram dalam rangka memeriahkan acara World Cup 2018 di Rusia. Konten hiburan ini bertujuan untuk mendukung tim Prancis yang melawan tim Kroasia.

Ketika suatu pesan iklan dapat dijadikan sebagai bahan hiburan yang berkualitas maka media sosial tersebut akan sangat digemari karena khalayak akan menunggu konten pesan selanjutnya yang dapat membangkitkan semangat sehingga mereka akan merasa terhibur atas pesan yang disampaikan. Lon Safko dan David K. Brake (2009) berpendapat bahwa dengan adanya konten hiburan dapat mendekatkan hubungan dengan audiens. IFI Bandung menyebarkan konten hiburan hanya ketika ada kegiatan tertentu. Penyampaian pesan juga harus diperhatikan, konten hiburan tidak boleh berlebihan mengingat IFI Bandung merupakan instansi resmi dibawah Kedutaan Besar Prancis. Disamping itu, IFI Bandung saat ini sedang membutuhkan konten hiburan baru untuk dapat mengembangkan media sosial Instagram IFI 
Bandung. Konten hiburan bukan perkara menyisipkan pesan hiburan pada media sosial, konten hiburan juga bukan bagian yang terpisah dari empat pilar strategi komunikasi. Semua pesan yang serius dapat disampaikan secara santai agar dapat dengan mudah diterima target audiens.

\section{SIMPULAN}

Pada buku Theories of Human Communication $11^{\text {th }}$ Edition karya Littlejohn menjelaskan bahwa teknologi merupakan sebuah alat yang ada di tangan manusia, dimana ponsel merupakan sarana komunikasi. Terdapat empat teori yang menjelaskan hubungan antara manusia dan teknologi, salah satunya adalah teori ketergantungan media. Pada teori ketergantungan media, hubungan yang diciptakan adalah hubungan yang saling bergantung, manusia sangat bergantung dan sangat dipengaruhi oleh konten dari media. Disamping itu, Media sosial Instagram IFI Bandung merupakan salah satu media yang digunakan untuk penyebaran informasi kursus dan kegiatan-kegiatan kebudayaan sehingga hubungan antara institusi dan khalayak saling bergantung pada konten media sosial Instagram IFI Bandung. Dimana, IFI Bandung menyebarkan informasi untuk menarik minat banyak orang dan khalayak membutuhkan informasi pesan tersebut untuk mendapatkan informasi secara lengkap dan jelas.

Strategi digital marketing pada konten media sosial Institut Français Indonesia Bandung@IFI_Bandung berdasarkan hasil penelitian dapat dilihat dari empat (4) poin sesuai dengan empat (4) pilar strategi media sosial yang dijelaskan oleh Lon Safko dan David K. Brake (2009), yaitu:

1. Komunikasi

Konten komunikasi yang baik yaitu mampu membangun percakapan dengan audiens karena kita tidak dapat mengontrol interaksi dan percakapan pada media 
sosial yang dapat dilakukan hanyalah mempengaruhi audiens tersebut. Konten pada media sosial Instagram @IFI_Bandung yang memuat aspek strategi komunikasi penyebarannya dilakukan oleh setiap bidang penanggungjawab masing-masing, Hal tersebut dilakukan dalam pengelolaan media sosial Instagram Institut Français Indonesia Bandung agar interaksi komunikasi dapat lebih terarah pada target market masing-masing.

2. Kolaborasi

Konten kolaborasi yang baik adalah yang mampu menjalin hubungan baik dengan berbagai komunitas. Institut Français Indonesia Bandung melakukan kolaborasi dengan berbagai komunitas dengan tujuan untuk membangun kerja sama (building partnership) yang baik sehingga nantinya ketika terdapat kegiatan lain akan mudah dalam berkoordinasi, penyebaraan informasi lebih meluas sehingga suatu kegiatan dapat berjalan dengan lancar.

\section{Edukasi}

Konten edukasi pada media sosial mampu membangun ikatan dengan target audiens karena konten media sosial yang bermanfaat merupakan salah satu proses berbagi ilmu secara terus menerus. Media sosial Instagram @IFI_Bandung memuat konten edukasi untuk melawan stigma belajar Bahasa Prancis tidak mudah.

\section{Hiburan}

Dengan adanya konten hiburan dapat mendekatkan hubungan dengan audiens. IFI Bandung menyebarkan konten hiburan hanya ketika ada kegiatan tertentu. Penyampaian pesan juga harus diperhatikan, konten hiburan tidak boleh 
berlebihan mengingat IFI Bandung merupakan instansi resmi dibawah Kedutaan Besar Prancis.

\section{SARAN}

\section{Saran Akademis}

Penelitian ini memerlukan observasi yang mendalam dan rutin dilakukan sehingga dapat menemukan analisa mengenai pengelolaan strategi konten digital marketing media sosial Institut Français Indonesia Bandung dan mampu mendeskripsikan secara baik dan benar. Untuk memperkuat dan memperjelas data yang digunakan, peneliti menyarankan kepada peneliti selanjutnya untuk memperbanyak literatur baik melalui jurnal maupun buku teori terutama terkait teori strategi media sosial Lon Safko dan David K. Brake (2009).

\section{Saran Praktis}

Berdasarkan informasi dari informan pendukung, media sosial suatu institusi harus mampu membangun interaksi sosial dengan target market. Maka dari itu, IFI Bandung harus memastikan untuk mampu menjadi hubungan yang aktif dan terus menerus dengan para pengikut di media sosial terutama Instagram. Selain itu, untuk memudahkan dalam melakukan komunikasi di media sosial, IFI Bandung harus memiliki satu admin yang bertugas mengelola media sosial secara penuh seperti membuat desain poster iklan yang akan disebar pada seluruh media sosial, menyusun jadwal penyebaran pesan pada media sosial, aktif merespon berbagai macam pertanyaan-pertanyaan ataupun masukan dari para pengikut media sosial IFI Bandung. Admin tersebut bisa dari luar struktur organisasi institusi seperti mahasiswa magang atau freelancer. Mengingat tugas penanggungjawab 
komunikasi dan budaya bukan hanya mengelola media sosial IFI Bandung saja namun juga mengurus kerja sama komunitas diluar instansi, mengurus kegiatan kebudayaan yang silih berganti dan lain-lain.

\section{DAFTAR PUSTAKA}

Ikbar, Yanuar. 2012. Metode Sosial Penelitian Kualitatif. Bandung : PT Refika Aditama Kriyantono, Rachmat. 2014. Teknik Praktis Riset Komunikasi. Jakarta: Prenadamedia Group.

Littlejohn, Stephen W \& Karen A.Foss, 2017. Theories of Human Communication Eleventh Edition. Long Grove, Illinois, United States: Waveland Press, Inc

Safko, Lon dan David K. Brake. 2009. The Social Media Bilble. New Jersey: Hoboken Sugiyono. 2015. Metode Penelitian Pendidikan. Bandung: Alfabeta

Tahir, Muh. 2011. Pengantar Metodologi Penelitian Pendidikan. Makassar: Universitas Muhammadiyah Makassar. 
108 Acta Diurna Vol 15 No 1 Tahun 2019 
